\section{Pulmonary embolism in a patient with neuroleptic malignant syndrome}

\author{
Mosaad Almegren \\ Department of Medicine, Al Imam \\ Mohammad Ibn Saud Islamic \\ University, Riyadh, Saudi Arabia
}

\begin{abstract}
Venous thromboembolism is one of the complications in patients prescribed antipsychotic medications. Neuroleptic malignant syndrome (NMS) is a rare side effect of antipsychotic medications in this population. In this case, a young patient, who presented with NMS after a recent start of antipsychotic medications, had developed a pulmonary embolism despite standard of care measures of venous thromboprophylaxis and early mobilization. A low threshold of VTE suspicion and effective preventive measures are both required in order to avoid this preventable complication in this population.
\end{abstract}

\section{Introduction}

Neuroleptic malignant syndrome (NMS) is a rare but serious psychiatric emergency condition classically found in patients who have started taking antipsychotic medications. It was first described in $1960 .{ }^{1}$ NMS has been recognized and described since that time especially with the increasing use of antipsychotic medications. Early recognition and diagnosis of NMS is critical for the management of this psychiatric emergency. Antipsychotic medications are a known risk for venous thromboembolism (VTE). ${ }^{2}$ In this paper, a case of pulmonary embolism in a patient diagnosed with NMS that was triggered by recently started atypical antipsychotic medications is described.

\section{Case Report}

A 29-year-old Caucasian male was admitted to the hospital for altered mental status in the form of abnormal behavior, mutism, and confusion, associated with diaphoresis, rigidity, and difficulty walking. He was started on quetiapine $100 \mathrm{mg}$ daily and risperidone $2 \mathrm{mg}$ daily for substance induced psychosis four days prior to this admission but no previous history of catatonia. On physical examination he had a temperature of $37.2 \mathrm{C}(98.9 \mathrm{~F})$, heart rate was 115 beats/minute, blood pressure was $133 / 79 \mathrm{~mm} / \mathrm{Hg}$, respiratory rate was $18 / \mathrm{min}$, and oxygen saturation was $97 \%$ in room air. He was lying in the bed and was conscious but not oriented. He had more diffuse rigidity in the lower limbs, however reflexes were not elicitable due to diffuse rigidity. The rest of his systemic examination was normal. He had a hemoglobin of $158 \mathrm{~g} / \mathrm{L}(135-175 \mathrm{~g} / \mathrm{L})$, white blood count $11.1 \times 10^{9} / \mathrm{L} \quad\left(4-11 \times 10^{9} / \mathrm{L}\right), \quad$ platelet $226 \times 10^{9} / \mathrm{L}\left(150-450 \times 10^{9} / \mathrm{L}\right)$, and creatinine kinase 3792 U/L (30-300 U/L). Serum electrolytes level, blood urea nitrogen, and creatinine were normal. The urine analysis and urine for the toxicology screen was negative. A computed tomography (CT) brain scan was normal.

A diagnosis of NMS was made. Quetiapine and risperidone were discontinued immediately. He was started on diazepam $15 \mathrm{mg}$ orally three times daily, bromocriptine $2.5 \mathrm{mg}$ orally twice daily, intravenous fluid, and pharmacological thromboprophylaxis with enoxaparin $40 \mathrm{mg}$ once daily. On day 1 of hospital admission, he had improved and was mobile with help of a physiotherapist. On day 3 , he was oriented, communicating normally, and fully mobile with a gradual improvement in his creatinine kinase. However, he complained of one episode of a small amount of hemoptysis. D-dimer was requested due to suspicion of pulmonary embolism (PE); it was $3.96 \mathrm{ug} / \mathrm{ml}$. A CT pulmonary angiography scan showed filling defects at the left main pulmonary artery, left lobar, segmental, and subsegmental branches (Figure 1). The patient was started on enoxaparin $(1 \mathrm{mg} / \mathrm{kg}$ twice daily) and warfarin in order to achieve a therapeutic international normalized ratio. Doppler ultrasound of the lower limbs excluded deep vein thrombosis. He was treated with warfarin for three months for a provoked pulmonary embolism without complications.

\section{Discussion}

NMS is a psychiatric emergency characterized by a change in mental status, fever, rigidity, and autonomic instability. ${ }^{3}$ The incidence rate is $0.01-3 \%$ of patients treated with antipsychotics and has a $5-10 \%$ mortality rate. ${ }^{4,5}$ The cause of NMS is unknown; dopamine receptor blockade, however, plays a central role in the pathogenesis that is responsible for the symptoms and signs of NMS. The onset usually devel-
Correspondence: Mosaad Almegren, College of Medicine, Al Imam Mohammad Ibn Saud Islamic University,

P.O. Box 7544, Othman Bin Affan road, Al Nada Riyadh, Kingdom of Saudi Arabia. Tel.: +966112037100 - Fax: +966112037108. E-mail: mosaad966@gmail.com

Key words: Pulmonary embolism, neuroleptic malignant syndrome, antipsychotic.

Conflict of interest: the author declares no potential conflict of interest.

Funding: none.

Received for publication: 21 May 2018

Revision received: 5 November 2018.

Accepted for publication: 16 November 2018.

This work is licensed under a Creative Commons Attribution-NonCommercial 4.0 International License (CC BY-NC 4.0).

(C) Copyright M. Almegren, 2018

Licensee PAGEPress, Italy

Hematology Reports 2018; 10:7753

doi:10.4081/hr.2018.7753

ops within $24 \mathrm{~h}$ to 30 days after administration of antipsychotic medications. ${ }^{6}$

Venous thromboembolism (VTE) is the third most common cause of vascular death following myocardial infarction and stroke. ${ }^{7}$ Thromboprophylaxis is highly recommended in patients at high risk for venous thrombosis. Immobilization, surgery, leg fractures, pregnancy, and cancer are all well known risk factors for VTE. Several observational studies and case reports have shown an association between antipsychotic medications and VTE. ${ }^{2}$ Immobilization and physical restraint were the most important provoking factors for the VTE in this population. ${ }^{2}$ In a case control study, antipsychotic medications increased the risk of VTE by 3.5 -fold. ${ }^{8}$ In another case control study of 25,532 patients, those who had been prescribed antipsychotic medications in the last two years had a $32 \%$ higher risk of VTE compared to nonusers. ${ }^{9}$ The relationship between antipsychotic medications and VTE was also evaluated in a meta-analysis of seven case control studies that showed double the risk of VTE in antipsychotic users when compared with the controls. ${ }^{10}$ NMS might be an underestimated risk factor for VTE in psychiatric patients. In another case report, pharmacological prophylaxis did not prevent an extensive deep vein thrombosis from developing in a patient diagnosed with NMS. ${ }^{11}$ In a recent case report, Reilly et al. reported a case of $\mathrm{PE}$ in a 49-year-old male with NMS despite 

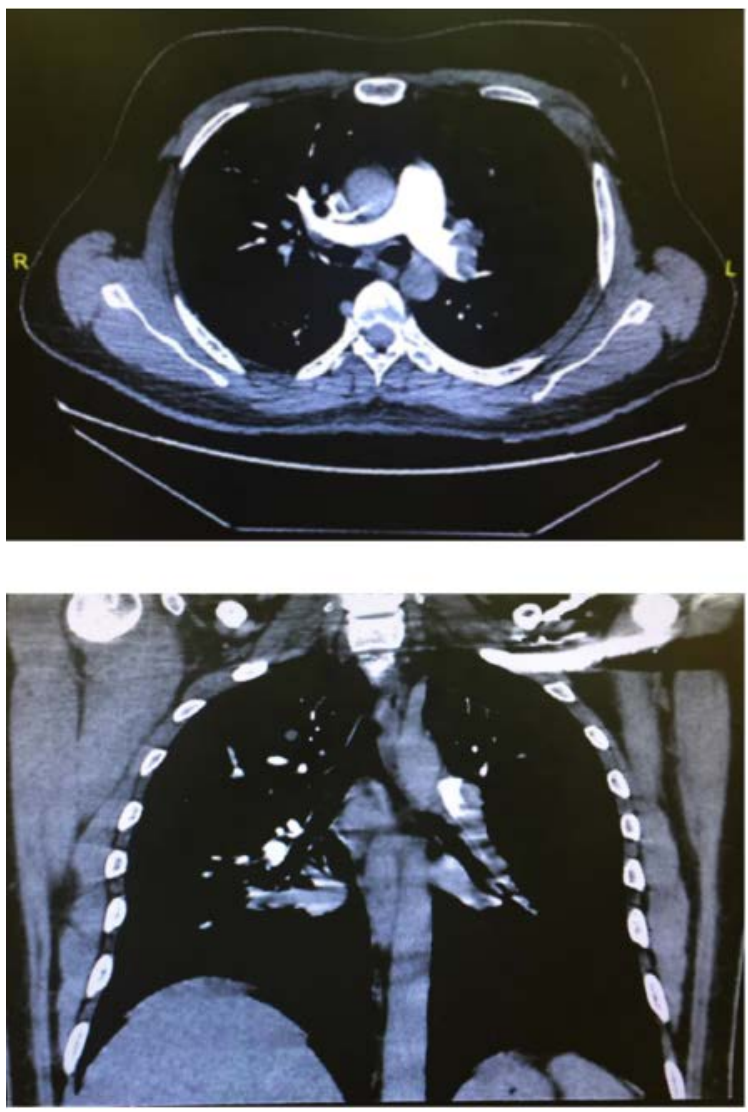

Figure 1. A CT pulmonary angiography scan showed filling defects at the left main pulmonary artery, left lobar, segmental, and subsegmental branches.

pharmacological thromboprophylaxis. ${ }^{12}$

In this case, the patient developed a significant pulmonary embolism despite the use of enoxaparin (40 $\mathrm{mg}$ ) as thromboprophylactic agent during admission and early mobility with an assistant on the first day and complete and independent mobility on the third day of admission. Antipsychotic medications were less likely to have been the cause of PE in this case as the medications were only started four days prior to hospital admission. It appears that NMS was the major provoking factor for this patient's VTE during his hospitalization.

\section{Conclusions}

The usual measures of VTE prevention (such as pharmacological prophylaxis and early mobilization) failed to protect against $\mathrm{PE}$ in this patient. Further measures should be considered in VTE prevention of patients with NMS, including higher doses or frequencies of pharmacological prophylaxis or a combination of mechanical and pharmacological measures.

\section{References}

1. Delay J, Pichot P, Lemperiere T, et al. A non-phenothiazine and non-reserpine major neuroleptic, haloperidol, in the treatment of psychoses. Ann Med Psychol (Paris) 1960;118:145-52.

2. Nester EGV, Verbrugger W, Leyer M. Deep vein thrombosis and pulmonary emboli in psychiatric settings. European J Psy 2009;23:19-30.

3. Caroff SN. The neuroleptic malignant syndrome. J Clin Psychiatry 1980; 4179-83.

4. Jeffrey R, Strawn MD, Paul E, et al. Neuroleptic malignant syndrome. Am J of Psy 2007; 164:6, 870-876.

5. Modi S, Dharaiya D, Schultz L. Varelas P. Neuroleptic Malignant Syndrome: Complications, Outcomes, and Mortality. Neurocrit Care 2016;24:97103.

6. Caroff SN, Mann SC. Neuroleptic malignant syndrome. Psychopharmacol Bull 1988;24:25-9.

7. Kearon C, Kahn SR, Agnelli G, et al. Antithrombotic therapy for venous thromboembolic disease: American College of Chest Physicians EvidenceBased Clinical Practice Guidelines (8th Edition). Chest. 2008;133:454S-5S.

8. Lacut K, Le Gal G, Couturaud F, et al. Association between antipsychotic drugs, antidepressant drugs and venous thromboembolism: results from the EDITH case-control study. Fundam Clin Pharm 2007;21643-50.

9. Parker C, Coupland C, Hippisley-Cox J. Antipsychotic drugs and risk of venous thromboembolism: Nested case-control study. BMJ 2010;341:c4245

10. Zhang R, Dong L, Shao F, et al. Antipsychotics and venous thromboembolism risk: A meta-analysis. Pharmacopsych 2011;44:183-8.

11. Mathew JC, Pillai U, Lacasse A. Extensive Deep Venous Thrombosis in a Patient with Neurolept Malignant Syndrome despite Being on Prophylaxis. Case Rep Psychiatry 2011:258172.

12. Reilly TJ, Cross S, Taylor DM, et al. Neuroleptic malignant syndrome following catatonia: Vigilance is the price of antipsychotic prescription. SAGE Open Med Case Rep 2017;5. 